\title{
Hand Surgery Fellowship Selection Criteria: A National Fellowship Director Survey
}

\author{
Francesco M. Egro, Sai K. Vangala, Vu T. Nguyen, Alexander M. Spiess \\ Department of Plastic Surgery, University of Pittsburgh Medical Center, Pittsburgh, PA, USA
}

Background Candidate characteristics for hand surgery fellowship training remains unknown, as very little data is available in the literature. This study aims to provide information on the criteria that are employed to select candidates for the hand surgery fellowship match.

Methods A 38-question survey was sent in April 2015 to all Accreditation Council for Graduate Medical Education recognized hand surgery fellowship program directors $(n=81)$ involved in the U.S. match. The survey investigated factors used for the selection of applicants, including medical school, residency training, research experience, fellowship interview, and candidate characteristics. A 5-point Likert scale was used to grade 33 factors from "not at all important" (1) to "essential in making my decision" (5); or for five controversial factors from "very negative impact" (1) to "very positive impact in making my decision" (5).

Results A total of 52\% (42 out of 81 ) of responses were received from hand surgery fellowship program directors. The most important influential factors were interactions with faculty during interview and visit $(4.6 \pm 0.6)$, interpersonal skills $(4.6 \pm 0.5)$, overall interview performance in the selection process $(4.6 \pm 0.6)$, professionalism and ethics $(4.6 \pm 0.7)$, and letters of recommendation from hand surgeons $(4.5 \pm 0.7)$. Factors that have a negative impact on the selection process include visa requirement (2.1 \pm 1.2$)$, graduate of non-plastic surgery residency program $(2.4 \pm 1.3)$, and graduate of a foreign medical school (2.4 \pm 1.1$)$.

Conclusions This study provides data on hand surgery fellowship directors' perception on the criteria important for fellowship applicant selection, and showed that interview-related criteria and letters of recommendation are the important factors.

Keywords Hand / Fellowships and scholarships / Surgery, plastic / Internship and residency
Correspondence: Francesco M. Egro Department of Plastic Surgery, University of Pittsburgh Medical Center, 3550 Terrace Street, 6B Scaife Hall, Pittsburgh, PA 15261, USA Tel: +1-412-648-9670 Fax: +412-648-1987 E-mail: francescoegro@gmail.com

Minor parts of the contents presented in this article were presented at the following conferences: American Association for Hand Surgery Annual Meeting, Scottsdale, AZ, January 2016; Plastic Surgery The Meeting, Boston, MA, October 2015; American Council of Academic Plastic Surgeons (ACAPS) Winter Retreat, Chicago, IL, February 2016. The abstract presented at the meeting was included in the PRS Global Open ACAPS Winter Retreat booklet.

No potential conflict of interest relevant to this article was reported.

Received: 19 Jan 2017 • Revised: 13 Jun 2017 • Accepted: 13 Jun 2017

pISSN: 2234-6163 • elSSN: 2234-6171 • https://doi.org/10.5999/aps.2017.44.5.428• Arch Plast Surg 2017;44:428-433

\section{INTRODUCTION}

Matching into hand surgery fellowship is very competitive, and requires applicants to employ careful consideration and planning skills. The understanding of the process is usually guided by hand surgery attendings, recent graduates or fellows. There is a lack of literature regarding the hand surgery fellowship match. Candidates who have completed or are approaching the com- pletion of training in either plastic surgery, orthopedic surgery, or general surgery are welcome to apply for a 1 year fellowship in hand surgery. Most hand surgery fellowships are approved by the Accreditation Council for Graduate Medical Education (ACGME). The match itself is a computerized algorithm that matches the applicant's rank order list of programs to the fellowship rank list order of applicants. Previous studies identified selection criteria for subspecialty fellowship programs in fields 
such as anesthesia, otolaryngology, orthopaedics and obstetrics and gynecology. However, very few studies investigate selection criteria of plastic surgery related fellowships [1-7].

The Combined Musculoskeletal-Hand Surgery Matching Program (CMMP) is administered by the National Resident Matching Program (NRMP) and is open to both orthopedic and plastic surgery residents [8]. A lot of research has investigated the matching process and selection criteria for plastic surgery residency [9-12]. At first glance it may seem that the important selection criteria on those studies may be applicable to the hand surgery fellowship. But the different demographic characteristics and background, make fellowship candidates unique. This subset of applicants is generally older, more mature, and has much more surgical experience. Due to these differences, it is important to appreciate that residency selection criteria are not transferable to fellowship, and thus requires detailed investigation of the factors that can lead to a successful hand surgery fellowship match.

We believed that there are consistent and specific characteristics that are preferred by hand fellowship program directors in the selection and ranking of applicants. The aim of this study is to evaluate the criteria used by fellowship directors when selecting candidates for training in hand surgery fellowship programs in the United States. It is the intent of this study to provide hand surgery fellowship applicants with accurate and valid information regarding selection criteria that will be applied while reviewing their applications. By identifying and reporting the selection criteria, future candidates will have improved insight into how to highlight their applications. Finally, there are definite benefits to the hand surgery program directors that can use this information to see how their program director colleagues also review applications.

\section{METHODS}

A 38-question survey was sent in April 2015 to all ACGME-recognized hand surgery fellowship program directors $(n=81)$ involved in the US match, by means of QuestionPro Survey Software (QuestionPro Inc., San Francisco, CA, USA). All of the programs participated in the CMMP run by the NRMP. After the initial email, follow-up emails were sent at 2-, 4-, and 6-week intervals to encourage program directors to submit their surveys.

The survey was an adapted version of the NRMP Program Director Survey sent in 2014. It was divided into sections of factors that were determined to be influential and controversial. Thirtythree influential factors were rated by fellowship directors on a Likert scale from 1 to 5 , with 1 being "not at all important in making the decision" and 5 being "essential to making the decision". Finally, these factors were further categorized into 5 categories including medical school, residency training, research experience, interview performance and "other" candidate characteristics.

Five characteristics where labeled as "controversial factors" due to fact that they may have a negative impact when evaluating a candidate. Because of this, a modified Likert scale was used, with 1 being "very negative impact in making the decision" and 5 being "very positive impact in making the decision."

All data was collected and processed using Excel (Microsoft Corp., Redmond, WA, USA), and the results were analyzed using IBM SPSS (IBM Corp., Armonk, NY, USA).

\section{RESULTS}

A total of 42 out of 81 directors responded to the survey, leading to a response rate of $52 \%$.

The most important influential factors ordered by highest mean Likert scores were interactions with faculty during interview and visit $(4.6 \pm 0.6)$, interpersonal skills $(4.6 \pm 0.5)$, overall interview performance in the selection process (4.6 \pm 0.6$)$, evidence of professionalism and ethics $(4.6 \pm 0.7)$, and letters of recommendation from hand surgeons $(4.5 \pm 0.7)$.

Whereas, the least important influential factors included having a $\mathrm{PhD}$ or equivalent $(1.7 \pm 0.9)$, Master's level graduate degrees (MPH, MBA, MS, or equivalent) $(1.7 \pm 0.8)$, research fellowship (2.0 \pm 0.9$)$, research grants awarded $(2.2 \pm 1.0)$, and audition elective/rotations $(2.3 \pm 1.3)$. The results of the influential factors are summarized in Table 1 and Fig. 1.

At the outset, all of the factors that were hypothesized as being detrimental to the success to the applicant in the matching process were confirmed by program directors as being deleterious. The factors that were reported as being the most negative were visa requirement $(2.1 \pm 1.2)$, graduate of non-plastic surgery residency program $(2.4 \pm 1.3)$, and graduate of a foreign medical school $(2.4 \pm 1.1)$. The results of the controversial factors are summarized in Table 2.

A comparison of the five influential factors' categories (medical school, residency, research, interview, others) was made (Table 3). By far, the most important category was the one related to the interview, with an average Likert response of $4.4 \pm 0.7$. The least important category was research with a combined average of $2.5 \pm 0.8$.

\section{DISCUSSION}

Graduating residents from orthopedic or plastic surgery pro- 


\section{Table 1. Response data for the influential factors including mean, SD, Var, Mln, Max}

\begin{tabular}{|c|c|c|c|c|c|c|}
\hline No. & Influential factor & Mean & SD & Var & Min & Max \\
\hline \multicolumn{7}{|c|}{ Medical school } \\
\hline 1 & Graduate of highly regarded U.S. medical school & 2.9 & 1.1 & 1.2 & 1 & 5 \\
\hline 2 & Medical school performance including medical transcript & 2.8 & 0.9 & 0.9 & 1 & 5 \\
\hline 3 & Alpha Omega Alpha (AOA) membership & 2.4 & 1.0 & 0.9 & 1 & 4 \\
\hline 4 & USMLE Step 1/COMLEX Level 1 score & 3.0 & 1.0 & 1.0 & 1 & 5 \\
\hline 5 & USMLE Step 2 Please define this abbreviation./COMLEX Level 2 CE score & 2.8 & 1.0 & 1.0 & 1 & 5 \\
\hline \multicolumn{7}{|c|}{ Residency } \\
\hline 6 & USMLE/COMLEX Step 3 score & 2.6 & 1.0 & 1.0 & 1 & 5 \\
\hline 7 & In-service exam scores & 2.4 & 1.0 & 0.9 & 1 & 5 \\
\hline 8 & Graduate of highly regarded U.S. plastic surgery residency program & 3.6 & 0.9 & 0.7 & 2 & 5 \\
\hline 9 & Letters of recommendation by hand surgeons & 4.5 & 0.7 & 0.5 & 2 & 5 \\
\hline 10 & Letters of recommendation by well-established plastic surgeons & 4.2 & 0.7 & 0.5 & 3 & 5 \\
\hline 11 & Personal statement & 3.0 & 0.8 & 0.7 & 1 & 4 \\
\hline \multicolumn{7}{|c|}{ Research } \\
\hline 12 & Demonstrated involvement and interest in basic science research & 2.8 & 0.9 & 0.9 & 1 & 5 \\
\hline 13 & Demonstrated involvement and interest in clinical research & 3.3 & 0.8 & 0.6 & 2 & 5 \\
\hline 14 & Demonstrated involvement and interest in hand surgery research & 3.3 & 0.8 & 0.7 & 1 & 5 \\
\hline 15 & MPH, MBA, MS, or equivalent & 1.7 & 0.8 & 0.7 & 1 & 4 \\
\hline 16 & PhD or equivalent & 1.7 & 0.9 & 0.7 & 1 & 4 \\
\hline 17 & Research fellowship & 2.0 & 0.9 & 0.8 & 1 & 4 \\
\hline 18 & Research grants awarded & 2.2 & 1.0 & 0.9 & 1 & 4 \\
\hline 19 & Honors and awards & 3.0 & 0.8 & 0.6 & 1 & 4 \\
\hline 20 & High volume of publications and presentations & 3.0 & 0.7 & 0.5 & 1 & 4 \\
\hline \multicolumn{7}{|c|}{ Interview } \\
\hline 21 & Overall interview performance in the selection process & 4.6 & 0.6 & 0.4 & 3 & 5 \\
\hline 22 & Interactions with faculty during interview and visit & 4.6 & 0.6 & 0.3 & 3 & 5 \\
\hline 23 & Interactions with housestaff during interview and visit & 4.4 & 0.7 & 0.5 & 3 & 5 \\
\hline 24 & Interpersonal skills & 4.6 & 0.5 & 0.2 & 4 & 5 \\
\hline 25 & Feedback from current residents and fellows & 4.2 & 0.9 & 0.8 & 2 & 5 \\
\hline 26 & Perceived commitment to hand surgery & 4.1 & 0.8 & 0.6 & 2 & 5 \\
\hline 27 & Evidence of professionalism and ethics & 4.6 & 0.7 & 0.5 & 3 & 5 \\
\hline 28 & Leadership qualities & 3.8 & 0.9 & 0.8 & 2 & 5 \\
\hline \multicolumn{7}{|l|}{ Other } \\
\hline 29 & Audition elective/rotation within your department & 2.3 & 1.3 & 1.6 & 1 & 5 \\
\hline 30 & Personal prior knowledge of the applicant & 3.2 & 1.3 & 1.8 & 1 & 5 \\
\hline 31 & Perceived interest in your program & 3.4 & 1.0 & 1.1 & 1 & 5 \\
\hline 32 & Other life/extracurricular experience & 3.1 & 0.8 & 0.6 & 1 & 5 \\
\hline 33 & Fluency in language(s) spoken by your patient population & 2.4 & 1.3 & 1.8 & 1 & 5 \\
\hline
\end{tabular}

\section{Table 2. Response data for controversial factors including mean, SD, Var, Mln, Max}

\begin{tabular}{|c|c|c|c|c|c|c|}
\hline No. & Controversial factor & Mean & SD & Var & Min & Max \\
\hline 34 & Graduate of foreign medical school & 2.4 & 1.1 & 1.1 & 1 & 5 \\
\hline 35 & Graduate of non-U.S. plastic surgery residency program & 2.6 & 1.4 & 1.8 & 1 & 5 \\
\hline 36 & Graduate of non-plastic surgery residency program (e.g., OMFS, ENT, etc) & 2.4 & 1.3 & 1.7 & 1 & 5 \\
\hline 37 & Candidate needing a visa (e.g., J1, H1B, etc.) & 2.1 & 1.2 & 1.4 & 1 & 5 \\
\hline 38 & Candidate plans to practice in the same city as the fellowship & 2.6 & 0.8 & 0.6 & 1 & 4 \\
\hline
\end{tabular}

grams are fortunate to have multiple career options: they may elect to directly go into practice or undertake subspecialty training through a fellowship program. One of the avenues is to un- dertake a hand surgery fellowship, which ensures that candidates thorough understanding of all aspects of hand surgery. Hand Surgery Fellowship program directors have the daunting 


\section{Fig. 1. Graphical representation of influential factors results}

The results of the influential factors are summarized illustrating the mean survey response score with standard deviation error bars. Bars indicate standard deviation. 1, not at all important in making my decision; 2, less important in making my decision; 3, important in making my decision; 4, very important in making my decision; 5, essential in making my decision; USMLE, United States Medical Licensing Examinations; COMLEX, Comprehensive Osteopathic Medical Licensing Examination of the United States; MPH, master of public health; MBA, master of business administration; MS, master of science.

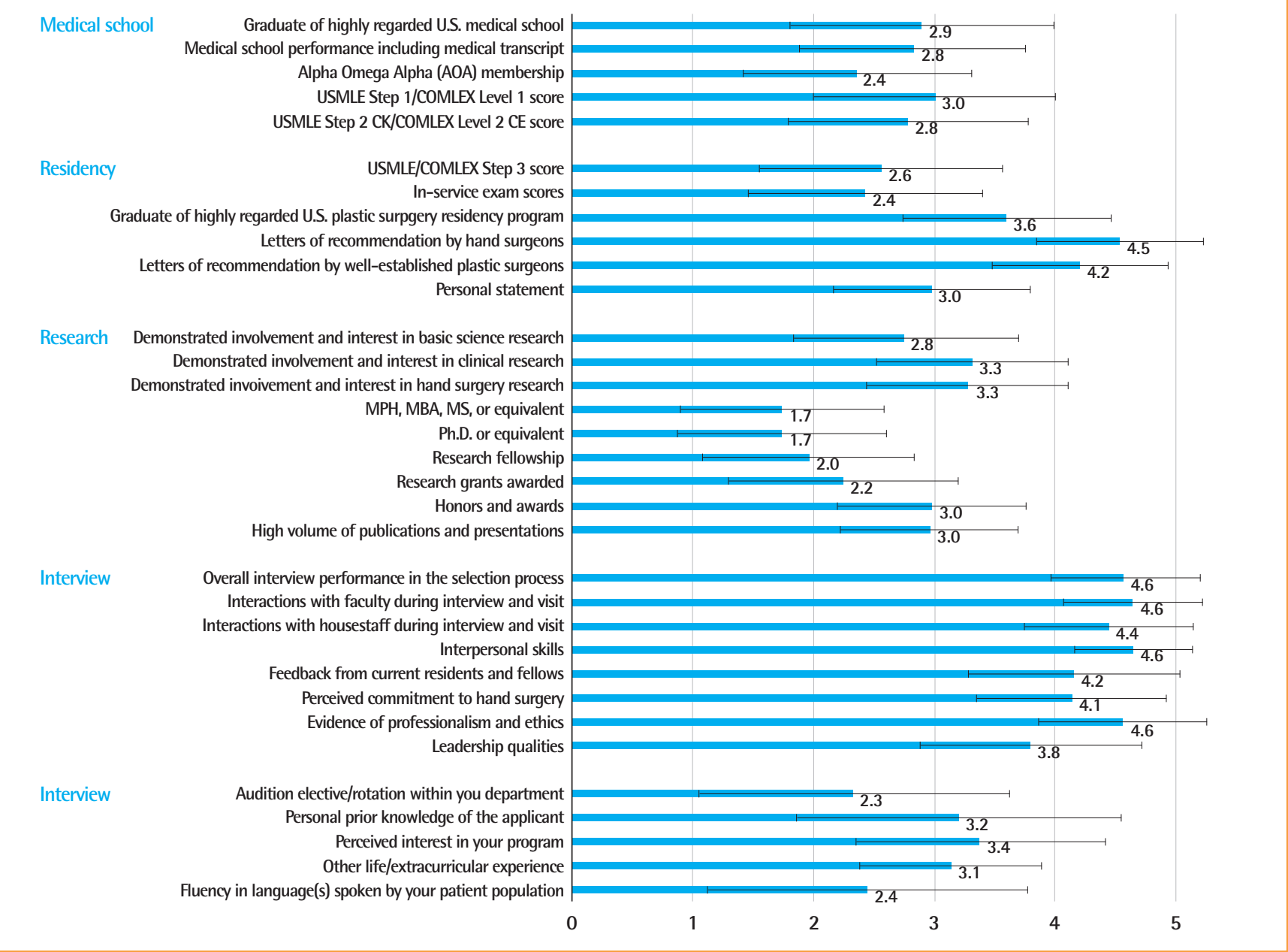

Table 3. Comparison of the influential factors' categories

\begin{tabular}{lccccc|}
\hline Category & Mean & SD & Var & Min & Max \\
\hline Medical school & 2.8 & 1.0 & 1.0 & 1 & 5 \\
Residency & 3.4 & 0.8 & 0.7 & 1 & 5 \\
Research & 2.5 & 0.8 & 0.7 & 1 & 5 \\
Interview & 4.4 & 0.7 & 0.5 & 2 & 5 \\
Other & 2.9 & 1.1 & 1.4 & 1 & 5 \\
\hline
\end{tabular}

SD, standard deviation; Var, variance; Min, minimum; Max, maximum.

task of having to assess the strengths of applicants who may seem to be at first glance to be equally competent for the job. Residents go through the application process with no data guiding them on the ideal characteristics, and have to rely on advice from peers and hand surgery attendings. This study outlines the most important selection criteria for hand fellowship programs as perceived by fellowship program directors; this study also shows that the most important selection criteria for hand fellowship programs differ from those criteria used in selecting candidates for plastic or orthopedic surgery residency programs.

One of the realities of modern day trainees is the continuous pressure to perform well among their peers at each stage of training. So by the time they reach fellowship applications, they all have similarly outstanding academic records. Thus, there are no objective metrics that can be used to evaluate their applications. This is in contrast to the heavy reliance on objective metrics (e.g., United States Medical Licensing Examinations, USMLEs) that have brought them to this stage of their careers [10-15]. According to the results of our study, one of the key differences in selection criteria between residency program directors and fellowship program directors, appears to be the fact that those ob- 
jective measures are given minimal importance, and are largely replaced with evaluations of a candidate's interpersonal skills and personal characteristics [1-7].

This perceived importance of objective measures might be diminished due to the nature of fellowship. The ability to interact well with colleagues and faculty, and interpersonal characteristics take a priority in fellowship candidate selection. Hand surgery fellows are required to work very closely with their mentors. This is in stark contrast to residency programs where a resident can expect to work with multiple attendings for brief periods at a time. Furthermore, while objective measures seem to correlate well with candidate performance during residency training, some studies show variable and inconsistent relationships between USMLE scores and fellowship performance [2]

After interpersonal skills, the most important elements were the quality of the letters of recommendation from hand surgeons and plastic surgeons ( $4.5 \pm 0.7$ and $4.2 \pm 0.7$, respectively). This finding represents the fact that a referees' judgment of a candidate is seemingly more important than test scores. Practicing hand surgeons are likely more capable of accurately assessing aptitude and suitability of an applicant to a career in hand surgery.

Hand surgery research-related characteristics were deemed to be of low importance to program directors $(2.5 \pm 0.8)$. Involvement in basic, clinical, or hand surgery research scored moderately higher in comparison to research fellowship or other postgraduate degrees. It appears that research activity is encouraged but holders of graduate degrees receive little advantage in the process.

Foreign-trained applicants provide numerous logistical and practical concerns that appear to lead hand surgery fellowship program directors to view their applications negatively. This phenomenon is certainly not unique to hand fellowship programs, but has been observed before among residency applicants as well [15]. Indeed, the subset of foreign applicants is very heterogeneous in their previous training experiences and quality of training. This makes it difficult to objectively compare domestic applicants and foreign ones. Domestic applicants represent a known quantity. Due to the variations in previous training experiences, mentor/mentee relationships may be difficult. This hesitation to view foreign applicants positively is unlikely related to language fluency since this is an item on the survey that was not viewed as being important $(2.4 \pm 1.3)$.

The validity of our findings was entirely dependent on the number of respondents. Any inferences can only be made using the data from program directors that responded to this survey. Previous research looking at fellowship selection criteria that relied on program director surveys had similar rates of response
[1-7]. The findings here may apply only to U.S. hand surgery fellowship programs and cannot be applied to international programs. Since the data was compiled through self-reported surveys, they may not represent actually behaviors or selection practices. Further studies are warranted to further clarify the rationale behind the perceived importance of the criteria, and perhaps to see how selection practices vary internationally.

To conclude, a definite lack of information regarding the competitiveness of plastic surgery fellowship programs exists since no dataset is available. This makes it difficult for prospective applicants to assess and tailor their curriculum for the fellowship they wish apply to. It also makes it more difficult for fellowship program directors to get an idea of how other programs view various criteria and thereby make adjustments in their own recruitment processes. The findings of this study offer current data regarding the perceived importance of a variety of applicant characteristics from hand surgery fellowship program directors. It is clear, that factors that assess a candidate's character qualitatively were found to be of greater value. It can be inferred that successful candidates are expected to work well in their groups and with their mentors to achieve training requirements and to ensure competence. We anticipate this data will help to inform future applicants and fellowship program directors of our subspecialty as they prepare for the match.

\section{REFERENCES}

1. Yung KC, Courey MS. Factors important in laryngology fellow and laryngology fellowship selection. Laryngoscope 2015;125:2543-6.

2. Natt N, Chang AY, Berbari EF, et al. Selection of endocrinology subspecialty trainees: which applicant characteristics are associated with performance during fellowship training? Endocr Pract 2016;22:45-50.

3. Grabowski G, Walker JW. Orthopaedic fellowship selection criteria: a survey of fellowship directors. J Bone Joint Surg Am 2013;95:e154.

4. Benzon HA, De Oliveira GS Jr, Jagannathan N, et al. Selection of subspecialty fellows in anesthesia for pediatric anesthesia: a national survey of program directors in the United States. Paediatr Anaesth 2015;25:487-91.

5. Meyer DR, Dewan MA. Fellowship selection criteria in ophthalmic plastic and reconstructive surgery. Ophthal Plast Reconstr Surg 2010;26:357-9.

6. Chun R, Preciado D, Brown DJ, et al. Choosing a fellow or fellowship: a survey of pediatric otolaryngologists. JAMA Otolaryngol Head Neck Surg 2014;140:102-5.

7. Muffly TM, Gibson K, Barber MD, et al. Factors used by 
minimally invasive gynecologic surgery fellowship directors to select their fellows. J Minim Invasive Gynecol 2011;18(6 Suppl):S65.

8. The Match [Internet]. Washington, DC: National Resident Matching Program; 2017 [cited 2017 Jun 2]. Available from: http://www.nrmp.org/about/.

9. Rohrich RJ, Rodriguez ED, Unger JG. How to put your best self forward in plastic surgery residency interviews. Plast Reconstr Surg 2016;137:379-82.

10. Janis JE, Hatef DA. Resident selection protocols in plastic surgery: a national survey of plastic surgery program directors. Plast Reconstr Surg 2008;122:1929-39.

11. Harper JG, Given KS, Pettitt B, et al. The independent plastic surgery match: an in-depth analysis of the applicants and process. Ann Plast Surg 2011;66:568-71.
12. Nguyen AT, Janis JE. Resident selection protocols in plastic surgery: a national survey of plastic surgery independent program directors. Plast Reconstr Surg 2012;130:459-69.

13. Gauer JL, Wolff JM, Jackson JB. Do MCAT scores predict USMLE scores? An analysis on 5 years of medical student data. Med Educ Online 2016;21:31795.

14. Dunleavy D, Sondheimer H, Castillo-Page L, et al. Medical school admissions: more than grades and test scores. AAMC Anal Brief 2011;11:1-2.

15. Go PH, Klaassen Z, Chamberlain RS. An ERAS-based survey evaluating demographics, United States Medical Licensing Examination Performance, and research experience between American medical graduates and United States citizen international medical graduates: is the bar higher on the continent? J Surg Educ 2012;69:143-8. 